\title{
Novel Leptin-Regulated Genes Revealed by Transcriptional Profiling of the Hypothalamic Paraventricular Nucleus
}

\author{
Yi-Chun Loraine Tung, Marcella Ma, Sarah Piper, Anthony Coll, Stephen O'Rahilly, and Giles S. H. Yeo \\ University of Cambridge Metabolic Research Laboratories, Institute of Metabolic Science, Addenbrooke's Hospital, Cambridge CB2 0QQ, United Kingdom
}

Leptin plays a major role in coordinating the integrated response of the CNS to changes in nutritional state. Neurons within the paraventricular nucleus (PVN) of the hypothalamus express leptin receptors and receive dense innervation from leptin receptor-expressing neurons in the arcuate nucleus. To obtain new insights into the effects of circulating leptin on PVN function, we compared global transcriptional profiles of laser-captured PVN from ad libitum fed mice versus $48 \mathrm{~h}$ fasted mice receiving either sham or leptin treatment intraperitoneally. Five hundred twenty-seven PVN-expressed genes were altered by fasting in a manner that was at least partially reversible by leptin. Consistent with previous reports, thyrotrophin releasing hormone mRNA levels were decreased by fasting but restored to fed levels with leptin treatment. mRNA levels of oxytocin, vasopressin, and somatostatin were also reduced by fasting and restored by leptin. Given the known effects of leptin on synaptic remodeling, it is notable that, among the top 15 genes that were positively

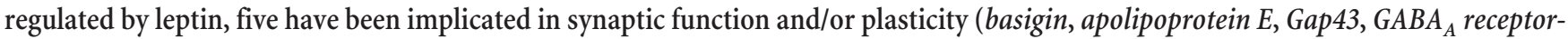
associated protein, and synuclein- $\gamma$ ). Pathway analysis identified oxidative phosphorylation, in particular, genes encoding complex 1 proteins that play a role in ubiquinone biosynthesis, to be the predominant gene set that was significantly regulated in a leptin-dependent manner. Thus, in addition to its effects on the expression of a broad range of neuropeptides, leptin may also exert more general influences on synaptic function in, and the bioenergetic state of, the PVN.

Key words: leptin; fasting; laser-captured microdissection; hypothalamus; paraventricular nucleus; microarray; gene

\section{Introduction}

Leptin is an adipocyte-derived hormone that plays a critical role in energy homeostasis. Circulating concentrations of leptin mirror fat cell stores, being increased in overfeeding but decreased with prolonged fasting. Robust data indicate that leptin acts primarily through the CNS to regulate food intake and energy expenditure (for review, see Coll et al., 2007; Oswal and Yeo, 2007). Within the CNS, the hypothalamus in particular is recognized to receive and integrate neural, metabolic, and humoral signals from the periphery. The hypothalamus is a heterogeneous region encompassing a number of anatomically discrete nuclei. For example, the arcuate nucleus (Arc) contains two distinct neuronal populations expressing either neuropeptide $\mathrm{Y}$ and agouti-related peptide (AgRP) or proopiomelanocortin and cocaine and amphetamine-related transcript. Both express the long form of the leptin receptor (ObRb) and are considered to be key firstorder neurons through which leptin exerts its effects.

Another important hypothalamic region involved in energy homeostasis is the paraventricular nucleus (PVN). In addition to containing neurons that themselves express ObRb, the PVN re-

\footnotetext{
Received July 21, 2008; revised 0ct. 4, 2008; accepted 0ct. 6, 2008.

This work was supported by the Medical Research Council Centre for Obesity and Related Metabolic Disease (United Kingdom), the Wellcome Trust, and European Union FP6 EUGENE2 Grant LSHM-CT-2004-512013.

Correspondence should be addressed to Giles S. H. Yeo, University of Cambridge Metabolic Research Laboratories, Level 4, Institute of Metabolic Science, Box 289, Addenbrooke's Hospital, Cambridge CB2 0QQ, UK. E-mail: gshy2@cam.ac.uk.

DOI:10.1523/JNEUROSCI.3412-08.2008

Copyright $\odot 2008$ Society for Neuroscience $\quad$ 0270-6474/08/2812419-08\$15.00/0
}

ceives dense innervation from leptin receptor-expressing neurons in the Arc, thereby allowing leptin to both directly and indirectly affect PVN neuronal activity. Furthermore, not only does lesioning of the PVN in rodents bring about marked hyperphagia, but also loss of a single allele of Sim1, a gene encoding a transcription factor critical for the normal development of the PVN (Michaud et al., 1998), causes obesity in both humans and mice (Holder et al., 2000; Michaud et al., 2001). Additionally, the reactivation of melanocortin 4-receptor $(\mathrm{Mc} 4 \mathrm{r})$ solely in the PVN completely corrects the hyperphagia found in Mc4r null mice (Balthasar et al., 2005), a well characterized obese mouse model of obesity resulting from disrupted central melanocortinergic signaling (Huszar et al., 1997).

The precise mechanisms by which changes in neuronal activity within these important hypothalamic nuclei are translated into changes in food intake and energy expenditure remains to be clearly established. In particular, the molecules and pathways that mediate the action of leptin in the PVN, either directly or indirectly via the melanocortin pathway, remain to be fully elucidated.

In this study, we have used laser-captured microdissection (LCM) coupled with transcriptional profiling to gain insights into the leptin-dependent mechanisms at work within the PVN. Reasoning that genes with a physiological role in energy homeostasis are likely to be nutritionally regulated, we have identified genes in the PVN whose expression is (1) altered in response to a substantial fast (a state of relative leptin deficiency) and (2) restored toward ad libitum fed values with leptin treatment alone. 
To allow discrimination between changes in gene expression that may have occurred as a result of the stress of fasting rather than via a leptin-dependent mechanism, we also analyzed in the same animals the transcriptome of the cerebellum, a brain region that does not express ObRb and has no known role in the control of energy balance.

\section{Materials and Methods}

In vivo murine studies. All animal studies were performed in male SV129 mice purchased from Charles River. Before all procedures, animals were allowed to acclimatize for at least 1 week. Animals were kept at $22^{\circ} \mathrm{C}$ on a $12 \mathrm{~h}$ light/dark cycle (lights on from 7:00 A.M. to 7:00 P.M.). The animals were fed on standard laboratory chow (Special Diet Services) and had access to water ad libitum throughout. All mice were matched for body weight at the start of the experiment. All experimental procedures were in accordance with regulations and guidelines of the United Kingdom Home Office.

We used the protocol as described by Ahima et al. (1996) for the maintenance of serum leptin levels during a fast. Ten-week-old mice were divided into three weight-matched groups $(n=4$ in each group for microarray; $n=8$ for TaqMan confirmation). Group one (fed) had ad libitum access to chow, and group two (fasted) had all food removed at the onset of light cycle and remained fasted for $48 \mathrm{~h}$. Both groups received twice daily intraperitoneal injection of saline. Group three (fasted plus leptin) had all food removed at the onset of light cycle and remained fasted for $48 \mathrm{~h}$ but received twice daily intraperitoneal injection of recombinant murine leptin (Amgen) at a dose of $1 \mu \mathrm{g} / \mathrm{g}$ total body weight. At the end of the experiment, the body weights of ad libitum fed, fasted, and fasted plus leptin mice were $28.1 \pm 0.5,22.7 \pm 0.3$, and $22.9 \pm 0.3 \mathrm{~g}$, respectively. All animals were killed by cervical dislocation $12 \mathrm{~h}$ after the last injection. The brains were removed and immediately frozen on powdered dry ice and stored at $-80^{\circ} \mathrm{C}$ until additional processing.

Laser-captured microdissection and total RNA isolation. Coronal sections of $14 \mu \mathrm{m}$ thickness were prepared on a cryostat and mounted on RNase-free membrane-coated glass slides (P.A.L.M. Membrane Slides; P.A.L.M. MicrolaserTechnologies). Slides were kept in a slide box embedded in dry ice until sectioning was completed. Within $24 \mathrm{~h}$ after sectioning, the frozen sections were thawed and fixed for $30 \mathrm{~s}$ in $95 \%$ ethanol and then rehydrated (75 and 50\% ethanol, $30 \mathrm{~s}$ each). After fixation, the slides were stained with $1 \%$ cresyl violet for $1 \mathrm{~min}$. The sections were then dehydrated in a graded ethanol series $(50 \%, 75 \%$, $95 \%$, and two times for $100 \%, 30 \mathrm{~s}$ each), followed by Histoclear for 5 min. All the solutions were prepared with RNase-free water (Ambion). Laser microdissection was performed using a P.A.L.M. MicrolaserSystem (P.A.L.M. Microlaser Technologies). The hypothalamic PVN was microdissected covering the region from -0.7 to $-1.22 \mathrm{~mm}$ caudal to bregma (37 sections) as defined by Paxinos and Franklin (2001). All evenly spaced sections were pooled to eliminate any potential rostrocaudal gene expression bias. After each microdissection, the captured cells were kept in RNAlater (Ambion) before RNA isolation. Total RNA was isolated according to the protocol of the manufacturer using the RNAqueousMicro kit (Ambion). Quality and quantity of the total RNA samples were determined by electrophoresis using the Agilent BioAnalyzer. Before RNA amplification, the more sensitive Agilent BioAnalyzer PicoChip was used (according to the instructions of the manufacturer). To determine the RNA concentration, a dilution series of a control with known concentration was run alongside the nuclei samples.

RNA amplification and microarray hybridization. To minimize bias, isolated total RNA ( $n=4$ per group) was subjected to two rounds of T7-based liner amplification. Briefly, RNA was primed with a T7 promoter oligo-dT primer and reverse transcribed to generate first-strand cDNA, which was used as the template to synthesize second-strand cDNA by DNA polymerase (Two-cycle cDNA Synthesis kit; Affymetrix). The T7 RNA polymerase promoter contained by double-stranded (ds) cDNA molecules was used, by T7 polymerase, to transcribe antisense amplified RNA (aRNA) (MEGAscript T7 kit; Ambion). The aRNA was then randomly primed to make single-stranded cDNA with a $3^{\prime}$ poly(A) tail to serve as the template for second-strand cDNA synthesis primed, as in the first round, with a T7 promoter oligo-dT primer to make ds cDNA containing a T7 promoter site. A second transcription step using T7 polymerase produced the second round of aRNA with biotin-labeled ribonucleotide (GeneChip IVT labeling kit; Affymetrix). The biotinlabeled cRNA were then fragmented, and the average fragment length was determined using an Agilent BioAnalyzer 2100 and hybridized to Affymetrix Murine 4302.0 oligonucleotide microarrays. The hybridized probe array is stained with streptavidin phycoerythrin conjugate and scanned on an Affymetrix GeneChip 7G scanner.

Microarray analysis. Raw image data were converted to CEL and pivot files using Affymetrix GeneChip Operating Software (GCOS). All downstream analysis of microarray data were performed using GeneSpring GX 7.3 (Agilent). The pivot files were used in the GCOS analysis and the CEL files were used for both the robust multiarray average (RMA) (Irizarry et al., 2003) and GCh robust multiarray average (GCRMA) (Wu et al., 2003) analyses. After importing the data, each chip was normalized to the 50th centile of the measurements taken from that chip, and all gene expression data are reported as fold change from the "fed" state. Genes were considered to be "leptin regulated" if they were significantly upregulated or downregulated by at least 1.5 -fold in the fasted state and (1) returned to within 1.3-fold of the fed state with leptin treatment or (2) changed by more than threefold from the fasted state with leptin treatment. Statistical analysis was performed using a one-sample Student's $t$ test, looking for statistically differentially expressed genes within each condition. The test was applied to the mean of each normalized value against the baseline value of 1 , at which genes do not show any differential expression with respect to the control. We considered $p \leq 0.05$ to be significant. Only genes that met the above criteria using GCOS, RMA, and GCRMA were taken forward for additional study.

Gene Tree "heat maps" were implemented by GeneSpring GX 7.3 using Pearson's correlation for similarity measure and an average linkage clustering algorithm. Pathway analysis was performed using Ingenuity Pathway Analysis (Ingenuity Systems).

Quantitative PCR analysis. Quantitative PCR (Q-PCR) analysis was performed using TaqMan Gene Expression assays on purified RNA samples. Total RNA were amplified as described for microarray. Two nanograms of isolated total RNA from each nucleus was subjected to two rounds of T7-based linear amplification. Amplified RNA, $100 \mathrm{ng}$, from laser-captured microdissected samples were used in a random-primed first-strand cDNA synthesis reaction, using superscript II reverse transcriptase (Invitrogen). The resulting first-strand cDNA reaction was diluted 2.5-fold, and $2 \mu \mathrm{l}$ was used in each $12 \mu \mathrm{l}$ of TaqMan reaction. Quantitative PCR reactions were performed in triplicate on an ABI 7900HT (Applied Biosystems) and using ABI PCR master mix, according to the protocols of the manufacturer. Expression results were normalized to $18 \mathrm{~S}, \beta$-actin, and B2M. Quantitative PCR statistical analysis was performed using Microsoft Excel. $p$ values were calculated using a two-tailed distribution unpaired Student's $t$ test. Data are expressed as mean \pm SEM.

\section{Results \\ Validation of laser capture and of fasting/fed/leptin paradigms}

To ensure the specificity of the PVN dissection (Fig. 1a) within laser-captured material, we examined expression of a number of genes that are only found in neighboring hypothalamic nuclei. As expected, we were unable to detect expression of ARCspecific Agrp, ventromedial nuclei-specific $S f-1$, and lateral hypothalamus-specific melanin concentrating hormone (Mch) within any PVN sample (data not shown). In addition, we examined expression of the gene encoding thyrotrophin releasing hormone (TRH), a well characterized hypothalamic peptide known to be highly expressed within the parvocellular region of the PVN (Flament-Durand, 1980) and known to be nutritionally regulated in a leptin-dependent manner (Hâkansson et al., 1998; Isse et al., 1999; Harris et al., 2001). Using TaqMan Q-PCR TRH 
a.
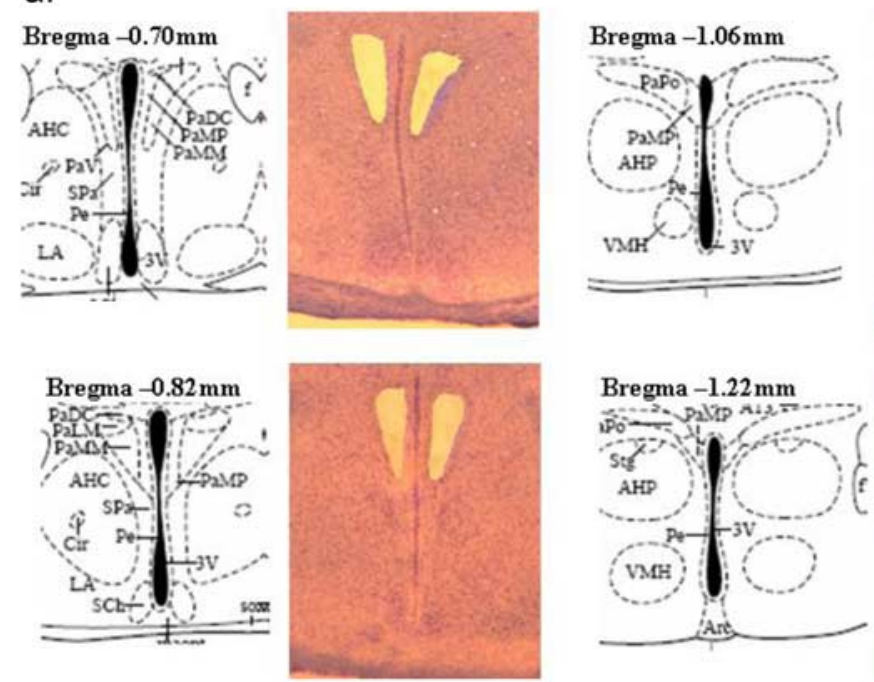

b.

TRH

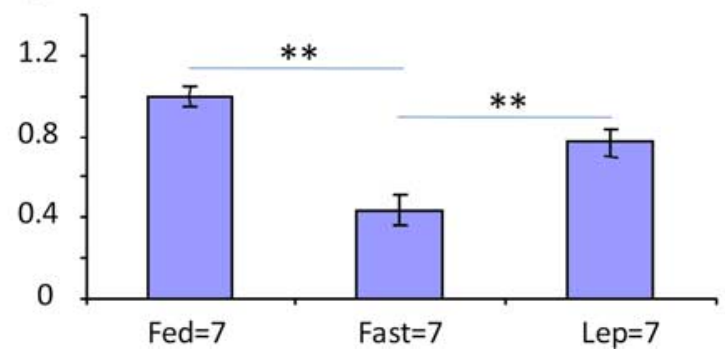

Figure 1. $\quad \boldsymbol{a}$, Laser-captured microdissection of the hypothalamic PVN. Brain atlas inserts are taken from Paxinos and Franklin (2001). $\boldsymbol{b}$, Trh is nutritionally and leptin regulated in the PVN. Bar graphs show the change in expression of Trh in the PVN of the hypothalamus in the fed, fasted, and leptin-treated-while-fasted state. Response is normalized to $18 \mathrm{~S}$ and is expressed in terms of fold induction of the fasted and leptin-treated expression over the fed expression. $p$ values were calculated using a two-tailed distribution unpaired Student's $t$ test. Data are represented as the mean \pm SE of at least six independent mice per group. ${ }^{* *} p<$ 0.01 .

a.

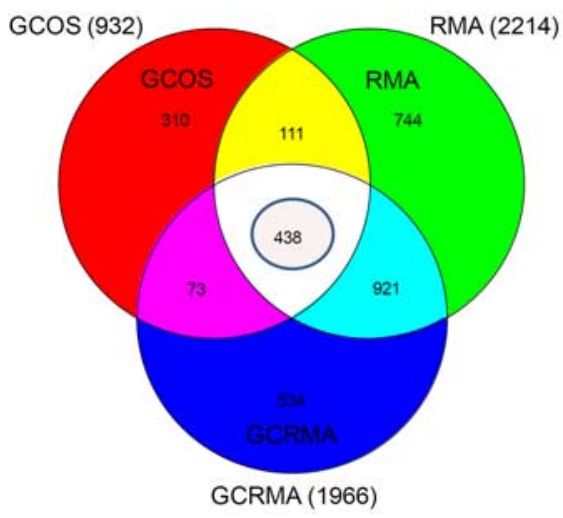

b.

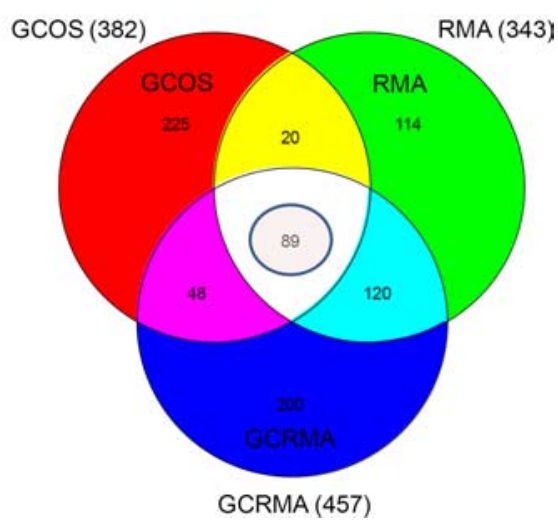

Figure 2. Venn diagram comparing the three different analyses: GCOS, RMA, and GCRMA. $a$, The 438 genes downregulated in fasting rescued by leptin. $\boldsymbol{b}$, The 89 genes upregulated in fasting rescued by leptin. Numbers in parentheses indicate the number of genes regulated by leptin (see Materials and Methods) as determined by either the GCOS, RMA, or GCRMA algorithms.

mRNA was decreased by fasting in LCM PVN samples, with this effect being significantly blunted by leptin replacement (Fig. 1b).

\section{Analysis of microarrays using three different algorithms}

We proceeded to hybridize the PVN RNA samples to murine whole genome oligonucleotide arrays (Affymetrix). To discrimi-
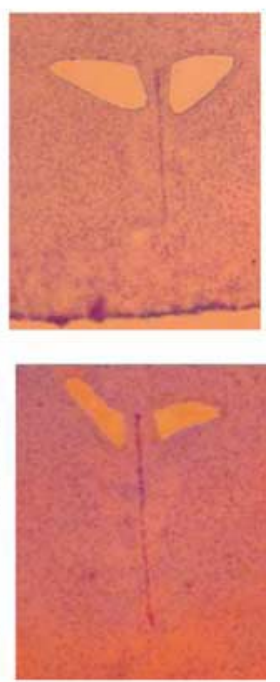

nate between $\mathrm{PVN}$-specific changes and a more generalized brain-wide response to stress of a prolonged fast, gene expression profiles were also obtained from samples of cerebellum removed from the same mice. All genes whose expression within the cerebellum was altered with fasting in a leptin-regulated manner were excluded from additional analysis $(n=280)$.

To maintain maximum stringency and reduce the number of false positives, we analyzed the data using three different algorithms: (1) GCOS, (2) RMA (Irizarry et al., 2003), and (3) GCRMA (Wu et al., 2003). Only genes whose expression patterns in each of the three analyses were identical were taken forward for additional study.

The three analyses gave very different results from the same experimental data. GCOS indicated that the expression of 932 genes were downregulated in fasting but returned toward fed levels with leptin (Fig. $2 a$ ). The number of genes with this expression profile was 2214 with RMA and 1966 with GCRMA, with only 438 genes having identical expression patterns across all three analytical platforms (Fig. 2a) (supplemental Table 1, available at www. jneurosci.org as supplemental material). Similar to genes upregulated by fasting but normalized with leptin, GCOS, RMA, and GCRMA analyses determined that 382, 343 , and 457 genes, respectively, followed this expression profile (Fig. $2 b$ ). Only 89 of these genes satisfied the criterion of concordance across all three analyses (supplemental Table 2, available at www. jneurosci.org as supplemental material).

Figure $3 a$ shows a heat map of the 527 leptin-regulated genes, and $b$ and $c$ represent the same data by plotting the average normalized signal intensities of the leptinregulated genes from the fasted (Fig. $3 b$ ) and fasted plus leptin (Fig. $3 c$ ) groups on the $y$-axes, respectively, against the fed group on the $x$-axis.

\section{Genes downregulated by fasting but normalized by leptin}

The major effect of leptin was to restore toward normal genes whose expression levels were downregulated by fasting. Figure $4 a$ lists the 25 transcripts that showed the largest downregulation in expression in the fasted state that were normalized by leptin. Consistent with our Q-PCR data (Fig. 1b), the fifth gene on this list is Trh, whose expression is downregulated 10 -fold in fasting and is rescued to $50 \%$ of fed levels. Among the top 25 genes positively regulated by leptin are two well known neuropeptides of the PVN, oxytocin and vasopressin. In addition, somatostatin gene expression (supplemental Table 1, available at www.jneurosci.org as supplemental mate- 
a.

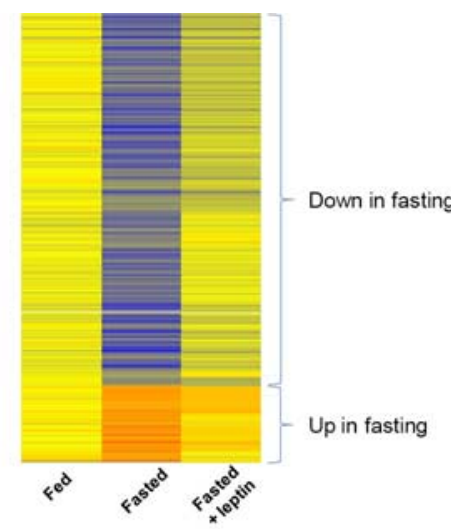

b.

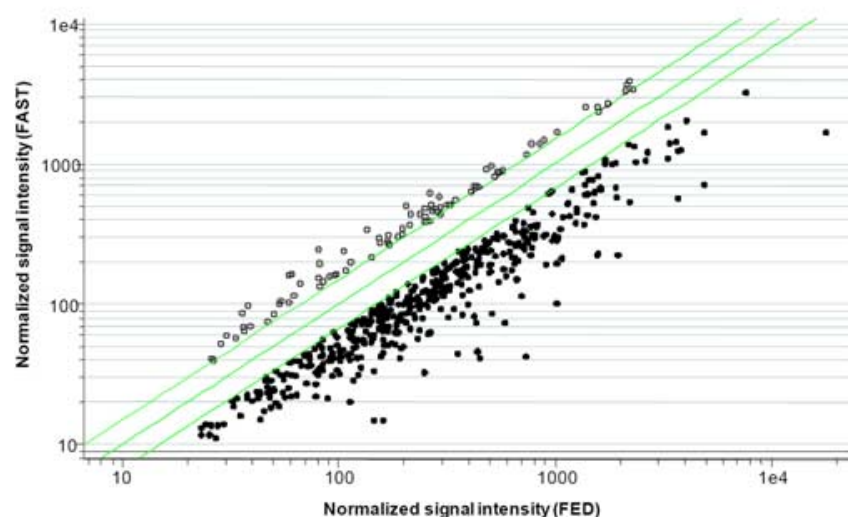

C.

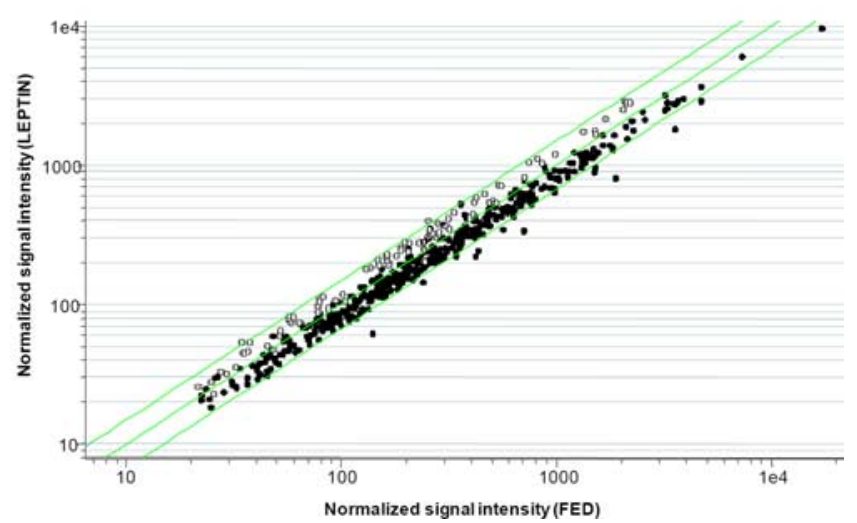

Figure 3. $a$, Heat map of 527 leptin-regulated genes. Blue color indicates downregulation, and red/orange color indicates upregulation compared with the fed state. $\boldsymbol{b}$, Scatter plot of 527 leptin-regulated genes in the fasting state. Plot of the average normalized signal intensities of the leptin-regulated genes from the fasted group on the $y$-axis against the fed group on the $x$-axis. Open circles represent the 89 genes upregulated in fasting, and filled circles represent the 438 genes downregulated in fasting. $c$, Scatter plot of 527 leptin-regulated genes when treated with leptin. Plot of the average normalized signal intensities of the leptin-regulated genes from the fasted plus leptin group on the $y$-axis against the fed group on the $x$-axis. Open circles represent the 89 genes upregulated in fasting, and filled circles represent the 438 genes downregulated in fasting.

rial) was significantly regulated in a similar manner. These data were validated in an independent biological replicate of this experiment using Q-PCR (Fig. 5a).

In addition to its role in regulation of neuropeptide expression, leptin has been shown recently to have important structural effects on synaptic density and remodeling within the arcuate nucleus (Pinto et al., 2004). Notably, among the top 25 genes positively regulated by leptin in the PVN (Fig. $4 a$ ) are several that have been implicated in synaptic function. These include the most highly leptin-regulated gene that we identified, namely basigin (Bsg), as well as apolipoprotein E (ApoE), Gap43, synuclein- $\gamma$, and $G A B A_{A}$ receptor-associated protein (Gabarap). The effects of leptin on the expression of Bsg, ApoE, Gap43, and Gabarap were also measured by Q-PCR in an independent biological replicated experiment. The direction of the effect was confirmed for all four genes, but, in the case of $A p o E$, this did not reach statistical significance (Fig. 5b).

The seventh gene on this list is neuronatin. It has been implicated to play a role in neurodevelopment and is also highly expressed in pancreatic $\beta$-cells in which it may play a role in insulin secretion (Joe et al., 2008) as well as in adipocytes (Suh et al., 2005). The expression profile of neuronatin was also validated by Q-PCR (Fig. 5b).

\section{Genes upregulated by fasting but normalized by leptin}

Figure $4 b$ lists the 25 transcripts that showed the greatest upregulation in expression in the fasted state that were normalized by leptin. The transcript at the top of the list is Netol (neuropilin and tolloid-like 1), which encodes a brain-specific transmembrane protein with structural similarity to neuropilin (Stöhr et al., 2002). Sorcs 1 (sortilin-related VPS10 domain containing receptor 1), the second gene on the list, has been implicated recently as a susceptibility gene in obesity-induced type 2 diabetes mellitus (T2D) (Clee et al., 2006; Goodarzi et al., 2007). Cntnap2, the fourth gene on the list, encodes a member of the neurexin family that functions in the vertebrate nervous system as cell adhesion molecules and receptors (Poliak et al., 1999).

\section{Pathway analysis}

We further analyzed the data using a pathway analysis package (Ingenuity Pathway Analysis) that detects groups of functionally related annotated genes.

The mitochondrial oxidative phosphorylation (OXPHOS) pathway was highly significantly over-represented ( $p=5.01 \mathrm{E}$ $16)$ in the list of genes whose expression was downregulated in fasting and reversed by leptin (Fig. 6). Twenty-six of 158 OXPHOS genes were present in the 438 genes. In particular, 12 of these genes were from the complex I ubiquinone biosynthesis pathway. To confirm this observation, we performed Q-PCR on eight OXPHOS genes present in a biological replicate of the experiment as described above. Three were from complex I (Ndufa8, Ndufb9, and $N d u f s 7$ ), one from each of complexes II, III, and IV (Sdhd, Uqcrc2, and Cox 5a, respectively), and two from complex V (Atp6vlf and Atp $5 g$ ). The OXPHOS genes from complexes I-IV showed fasting-induced downregulation that was reversed by leptin (Fig. 7); Atp6v1f and Atp5g from complex V showed no change in expression (data not shown). In keeping with the microarray results, the fasting-induced expression downregulation of these six genes was modest (between 1.5-fold and 2-fold downregulated), with only the downregulation of Ndufa8, Sdhd, and Cox5a reaching statistical significance ( $p<$ $0.05)$. However, the trend to downregulation and the reversal by leptin was present in all six genes, supporting the pathway analysis and providing additional evidence that multiple genes from the OXPHOS pathway are downregulated in the PVN in response to fasting and are regulated by leptin.

Genes involved in protein synthesis are also significantly $(p=$ $8.83 \mathrm{E}-6)$ over-represented in our list of genes positively regulated by leptin, with 41 of the 438 genes (9.3\%) involved. 


\section{a. Top 25 genes positively regulated by leptin}

\begin{tabular}{|c|c|c|c|c|c|}
\hline Affymetrix ID & Fast & Leptin & Genbank & Gene & Description \\
\hline 1456616_a_at & -19.40 & -2.69 & AV035166 & Bsg & Basigin \\
\hline 1451285_at & -13.45 & -1.86 & AF224264 & Fus & fusion, derived from $\mathrm{t}(12 ; 16)$ malignant liposarcoma (human) \\
\hline 1423548_s_at & -12.41 & -1.98 & BB556862 & Ergic3 & ERGIC and golgi 3 \\
\hline 1432466 a_at & -11.69 & -1.92 & AK019319 & Apoe & apolipoprotein E \\
\hline 1418756_at & -10.81 & -2.01 & NM_009426 & Trh & thyrotropin releasing hormone \\
\hline 1420556_at & -10.75 & -2.14 & NM_011025 & Oxt & oxytocin \\
\hline 1423506_a_at & -10.52 & -2.39 & AV218841 & Nnat & Neuronatin \\
\hline 1423537_at & -10.33 & -2.90 & BB622036 & Gap43 & Growth associated protein 43 \\
\hline 1429786_a_at & -10.09 & -2.97 & АК008144 & Zwint & ZW10 interactor \\
\hline 1427773_a_at & -9.35 & -1.76 & L40934 & Rabac1 & Rab acceptor 1 (prenylated) \\
\hline 1417788_at & -8.97 & -2.32 & NM_011430 & Sncg & synuclein, gamma \\
\hline 1416013_at & -8.87 & -1.79 & NM_011116 & PId3 & phospholipase $D$ family, member 3 \\
\hline 1422884_at & -8.47 & -2.46 & NM_026095 & Snrpd3 & small nuclear ribonucleoprotein D3 \\
\hline 1450694_at & -8.09 & -2.33 & NM_008020 & Fkbp2 & FK506 binding protein 2 \\
\hline 1416937_at & -7.97 & -1.50 & BC024621 & Gabarap & gamma-aminobutyric acid receptor associated protein \\
\hline 1450372_a_at & -7.87 & -1.44 & NM_009077 & Rpl18 & ribosomal protein $\mathrm{L} 18$ \\
\hline 1451695_a_at & -7.31 & -1.32 & AF274027 & Gpx4 & glutathione peroxidase 4 \\
\hline 1450794_at & -6.80 & -1.91 & NM_009732 & Avp & arginine vasopressin \\
\hline 1423916_s_at & -6.78 & -1.44 & BC003975 & MIf2 & myeloid leukemia factor 2 \\
\hline 1422797_at & -6.56 & -1.10 & NM_031248 & Mapbpip & mitogen activated protein binding protein interacting protein \\
\hline 1426710_at & -6.54 & -1.82 & BB396904 & Calm3 & Calmodulin 3 \\
\hline 1416965_at & -5.63 & 1.03 & AF181560 & Pcsk1n & proprotein convertase subtilisin/kexin type 1 inhibitor \\
\hline 1416026_a_at & -5.01 & -1.45 & NM_009076 & Rpl12 & ribosomal protein L12 \\
\hline 1416228_at & -4.99 & -1.29 & NM_023371 & Pin1 & protein (peptidyl-prolyl cis/trans isomerase) NIMA-interacting 1 \\
\hline 1440254_at & -4.94 & -1.47 & W65070 & & Transcribed locus \\
\hline
\end{tabular}

\section{b. Top 25 genes negatively regulated by leptin}

\begin{tabular}{|c|c|c|c|c|c|}
\hline Affymetrix ID & Fast & Leptin & Genbank & Gene & Description \\
\hline 1441815_at & 2.82 & 1.24 & Al851453 & Neto1 & neuropilin (NRP) and tolloid (TLL)-like 1 \\
\hline 1436662_at & 2.61 & 1.21 & BB022723 & Sorcs1 & VPS10 domain receptor protein SORCS 1 \\
\hline 1440853_at & 2.60 & 1.05 & BB432528 & Rhot1 & Ras homolog gene family, member T1 \\
\hline 1437782_at & 2.56 & 1.36 & BE651445 & Cntnap2 & contactin associated protein-like 2 \\
\hline 1417071_s_at & 2.47 & 1.38 & NM_133969 & Сур4v3 & cytochrome P450, family 4 , subfamily v, polypeptide 3 \\
\hline 1441905 x at at & 2.45 & 1.32 & BB264453 & Snrpn & Small nuclear ribonucleoprotein $\mathrm{N}$ \\
\hline 1457248 _x_at & 2.39 & 1.43 & BB554029 & Hsd17b7 & hydroxysteroid (17-beta) dehydrogenase 7 \\
\hline 1435092_at & 2.38 & 1.47 & AV328143 & Arl4a & ADP-ribosylation factor-like $4 \mathrm{~A}$ \\
\hline 1428529_at & 2.36 & 1.46 & AK012825 & 2810026P18Rik & RIKEN CDNA 2810026P18 gene \\
\hline 1456130_at & 2.28 & 1.17 & BG068705 & LOC553091 & Hypothetical LOC553091 \\
\hline 1431820_at & 2.27 & 1.20 & AK014549 & 4632404H12Rik & RIKEN CDNA 4632404H12 gene \\
\hline 1434509_at & 2.10 & 1.18 & BM250883 & Rapgef6 & Rap guanine nucleotide exchange factor (GEF) 6 \\
\hline 1417770 _s_at & 2.04 & 1.30 & AW208944 & Psmc6 & proteasome (prosome, macropain) $26 \mathrm{~S}$ subunit, ATPase, 6 \\
\hline 1441870 s_at & 2.03 & 1.30 & BB249222 & Pkd2 & polycystic kidney disease 2 \\
\hline 1443830 x_at & 1.95 & 1.09 & AV337847 & Rnf103 & AV337847 RIKEN full-length enriched \\
\hline 1441980_at & 1.95 & 1.19 & Вв355593 & C030007I09Rik & RIKEN cDNA C030007I09 gene \\
\hline 1439824_at & 1.93 & 1.08 & BB263701 & Chm & Choroidermia \\
\hline 1456698_s_at & 1.93 & 1.34 & BB711246 & Hnrpdl & heterogeneous nuclear ribonucleoprotein D-like \\
\hline 1434996_at & 1.91 & 1.21 & AV316233 & Slc25a16 & solute carrier family 25, member 16 \\
\hline 1447849_s_at & 1.91 & 1.01 & AV323441 & Maf & AV323441 RIKEN full-length enriched \\
\hline 1438168 x_at & 1.88 & 1.39 & AV214253 & Ddx39 & DEAD (Asp-Glu-Ala-Asp) box polypeptide 39 \\
\hline 1447898_s_at & 1.88 & 1.34 & Bв054483 & Sfrs6 & splicing factor, arginine/serine-rich 6 \\
\hline 1439012_a_at & 1.86 & 1.17 & ВВ030204 & Dck & deoxycytidine kinase \\
\hline 1455643_s_at & 1.86 & 1.19 & BF228294 & Tsr1 & TSR1, 20S rRNA accumulation, homolog (yeast) \\
\hline 1428224_at & 1.86 & 1.15 & AV101245 & Hnrpdl & heterogeneous nuclear ribonucleoprotein D-like \\
\hline
\end{tabular}

Figure 4. Top 25 genes that are positively $(\boldsymbol{a})$ and negatively $(\boldsymbol{b})$ regulated by leptin in the PVN. Changes in gene expression are expressed as fold induction of the fasted or leptin-treated expression over the respective fed expression. Negative numbers indicate downregulation. Genes are ranked by fasting fold change. Genes were considered to be leptin regulated if they were significantly upregulated or downregulated by at least 1.5 -fold in the fasted state and returned to within 1.3 -fold of the fed state with leptin treatment or changed by more than threefold from the fasted state with leptin treatment.

\section{Discussion}

To gain insights into molecules and pathways mediating downstream signaling actions of leptin in the PVN, a key hypothalamic region involved in energy balance, we compared the expression profiles of laser-captured PVN from ad libitum fed mice, $48 \mathrm{~h}$ fasted mice, and mice given leptin during a similar fast. To exclude transcripts representing nonspecific neuronal stress responses to fasting, we simultaneously profiled the cerebellum, a site unknown to have a regulatory role in energy balance. The specificity of the LCM could be confirmed visually (Fig. $1 a$ ) and is also supported by the absence of Agrp, Sf-1, and Mch transcripts from the samples. Additionally, we confirmed using Q-PCR that the PVN samples showed the expected regulation of TRH mRNA by fasting and feeding.
To minimize false positives, we were stringent in handling our data. Rather than rely solely on Affymetrix GCOS software, we also analyzed our data using RMA and GCRMA. After applying these different analyses, only $20-30 \%$ of all the genes overlapped between all three algorithms. However, it was clear that the biggest dataset $(n=438)$ was of genes positively regulated by leptin.

\section{Neuropeptide gene expression positively regulated by leptin}

Oxytocin, vasopressin, and somatostatin gene expression was reduced by fasting and restored by leptin (Fig. $5 a$ ). This is consistent with reports showing a fasting reduction in hypothalamic oxytocin mRNA levels that was reversed by refeeding (Kublaoui et al., 2008) and the reported role of oxytocin neurons linking hypothalamic leptin-action to caudal brainstem nuclei controlling meal size (Blevins et al., 2004). Arginine vasopressin expression in the PVN has been shown to be increased by leptin (Yamamoto et al., 1999). Previous reports demonstrating the presence of leptin receptors on PVN magnocellular vasopressin- and oxytocincontaining neurons (Hâkansson et al., 1998) indicate that this effect could result from direct leptin action. Additionally, somatostatin has been demonstrated to modulate the efficacy of leptin signaling in the rat hypothalamus (Stepanyan et al., 2007).

\section{Synaptic remodeling/plasticity genes positively regulated by leptin}

Four of the top 15 genes positively regulated by leptin (Basigin, ApoE, Gap43, and Gabarap) are involved in synaptic maintenance or development. Bsg is part of a transsynaptic complex regulating synaptic compartmentalization and strength, and coordinating plasma membrane and cortical organization (Besse et al., 2007). ApoE receptors act as signaling molecules in neurons, altering phosphorylation of numerous proteins after extracellular ligand binding and affecting neurite outgrowth, synapse formation, and neuronal migration (Hoe et al., 2006). Gap43 is a neuronal-specific gene that plays a role in actin regulation, neurite outgrowth, and anatomical plasticity (Frey et al., 2000). Gabarap traffics $\mathrm{GABA}_{\mathrm{A}}$ receptors to and from the cell surface, clustering these neurotransmitter receptors at the postsynaptic terminals (Chen et al., 2000; Leil et al., 2004), which is a critical requirement for efficient neurotransmission and neuronal communication.

It is becoming clear that, in addition to engaging classical "neuropeptide/receptor" systems within the brain, leptin also rapidly modifies synaptic connections between neurons. Leptin has been demonstrated to be necessary for both normal development of neuronal projections within the hypothalamus (Bouret 

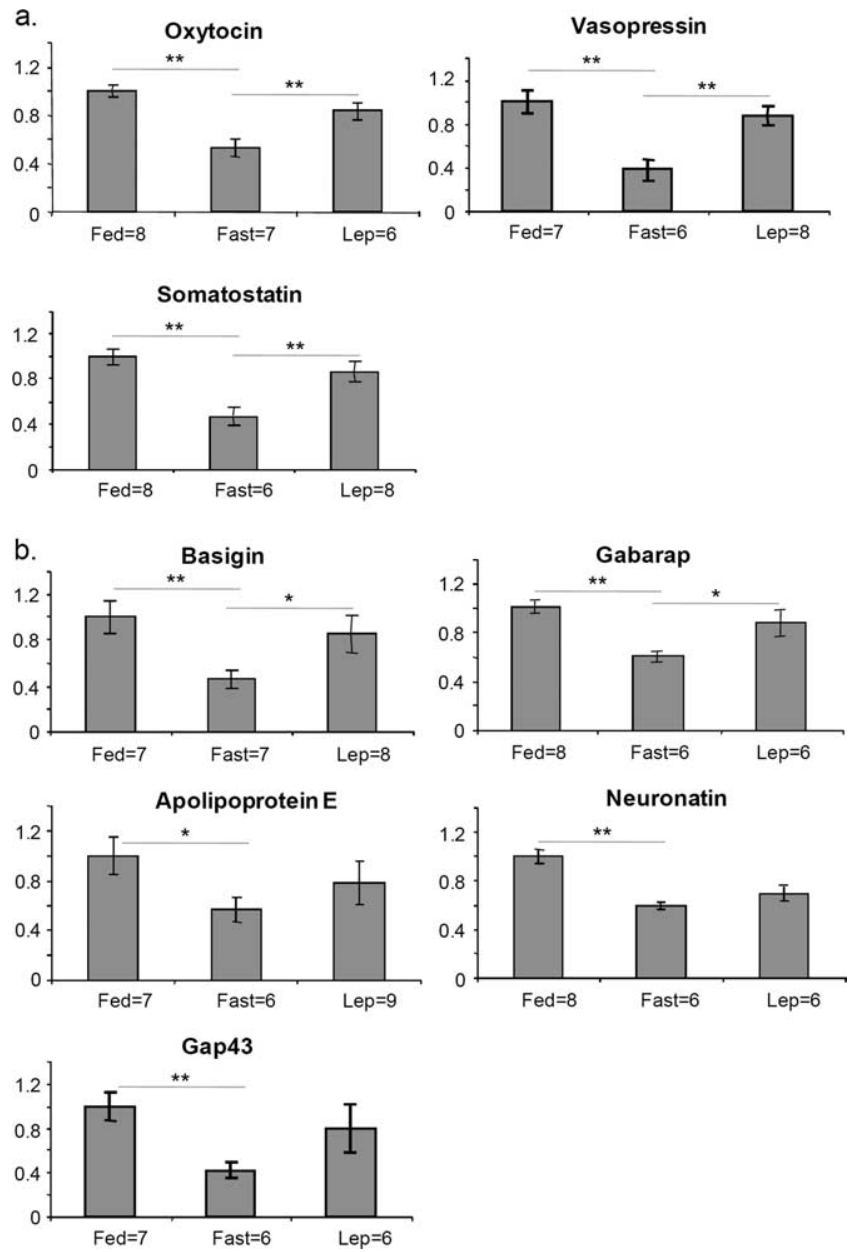

Figure 5. TaqMan quantitative $P C R$ validation of genes positively regulated by leptin. Bar graphs show the change in expression of neuroendocrine genes $(\boldsymbol{a})$ and genes involved in neuronal development $(\boldsymbol{b})$ in the PVN of the hypothalamus in the fed, fasted, and leptintreated-while-fasted state. Response is normalized to $18 \mathrm{~S}$ and is expressed in terms of fold induction of the fasted and leptin-treated expression over the fed expression. $p$ values were calculated using a two-tailed distribution unpaired Student's $t$ test. Data are represented as the mean \pm SE of at least six independent mice per group. ${ }^{*} p<0.05$; ${ }^{* *} p<0.01$.

et al., 2004) as well as in the regulation of synaptic plasticity (Pinto et al., 2004; Horvath and Gao, 2005; Sternson et al., 2005; Gao et al., 2007). The use-dependent potentiation of excitatory synapses onto pyramidal cells in the hippocampus is a well studied form of synaptic plasticity (Kullmann and Lamsa, 2007). The identification in this study of leptin-regulated genes that play a variety of roles in synapse development or plasticity supports the notion that similar mechanisms to those seen in the hippocampus (O'Malley et al.,2007) maybe active within the hypothalamus.

\section{Genes expressed in the brain and periphery positively regulated by leptin}

Neuronatin and synuclein- $\gamma$ are highly expressed in both the brain and metabolic relevant peripheral tissues. Neuronatin was first identified in the developing mammalian brain (Joseph et al., 1994) but is also expressed in the pancreas in which it plays a role in insulin secretion (Joe et al., 2008) and in adipocytes in which it may have a role in adipogenesis (Suh et al., 2005). Synuclein- $\gamma$ is abundant in the neuronal cytosol and enriched at presynaptic terminals (Clayton and George, 1998). However, like neuronatin,

\section{Ingenuity Pathway analyses of the 438 genes positively regulated by leptin}

\author{
Pathway \\ Oxidative Phosphorylation \\ Mitochondrial Dysfunction \\ Ubiquinone Biosynthesis \\ Protein Ubiquitination Pathway \\ Galactose Metabolism \\ Molecular and Cellular Function \\ Protein Synthesis \\ Small Molecule Biochemistry \\ Lipid Metabolism \\ Molecular Transport \\ Carbohydrate Metabolism
}

p-value

ratio

5.01E-16

8.71E-09

26/158

$17 / 165$

1.15E-08 12/104

1.29E-04 14/202

6.03E-03 5/112

p-value

8.83E-06

\# molecules

4.66E-04

41

$1.58 \mathrm{E}-03$

42

$1.58 \mathrm{E}-03$

20

$1.75 \mathrm{E}-03$

32

15

Figure 6. Ingenuity pathway analysis of 438 genes positively regulated by leptin.

it has also been found to be highly expressed in white adipose tissue, in which it is coordinately expressed with leptin and increased in human obesity (Oort et al., 2008). It is intriguing that adipose tissue and leptin-responsive neurons in the brain could share some nutrient-sensing mechanisms.

\section{Genes negatively regulated by leptin}

Our data indicates that there are fewer genes that are negatively regulated by leptin. However, the first (Neto1) and the fourth (Cntnap2) genes on this list also have a role in neuronal development. Netol encodes a brain-specific transmembrane protein, whose expression pattern and structural similarity with neuropilin suggested that it possibly played a role in the development and/or maintenance of neuronal circuitry (Stöhr et al., 2002), whereas Cntnap2 is a member of the neurexin family, which functions in vertebrate nervous systems as cell adhesion molecules and receptors (Poliak et al., 1999). Thus, it appears that leptin can positively and negatively regulate genes involved in neuronal development, providing more evidence that structural changes to hypothalamic neurons may play a role in mediating the actions of leptin.

Sorcs1, another gene negatively regulated by leptin, was identified in mice as a quantitative trait locus for T2D affecting fasting insulin levels (Clee et al., 2006). A recent study translating these results in humans identified significant associations between SORCS1 variants and fasting insulin levels, as well as T2D risk in female subjects, in two Mexican-American populations. Goodarzi et al. (2007) has hypothesized that it may play a role in the maintenance or expansion of islet vasculature during islet growth in compensation for insulin resistance. However, SORCS1 is also highly expressed in neurons in which it probably plays a role in cell trafficking, with one of its major isoforms interacting with the $\alpha \mathrm{C} / \sigma 2$ subunits of the adaptor protein- 2 complex (Nielsen et al., 2008). The fact that this gene is nutritionally regulated in a leptindependent manner warrants additional investigation.

\section{Pathway analysis}

To identify pathways or functional annotations that maybe overrepresented in the expression data, we performed pathway analyses of genes both positively and negatively regulated by leptin. We did not identify any coordinated pathways or functions negatively regulated by leptin. However, analysis of the 438 genes 


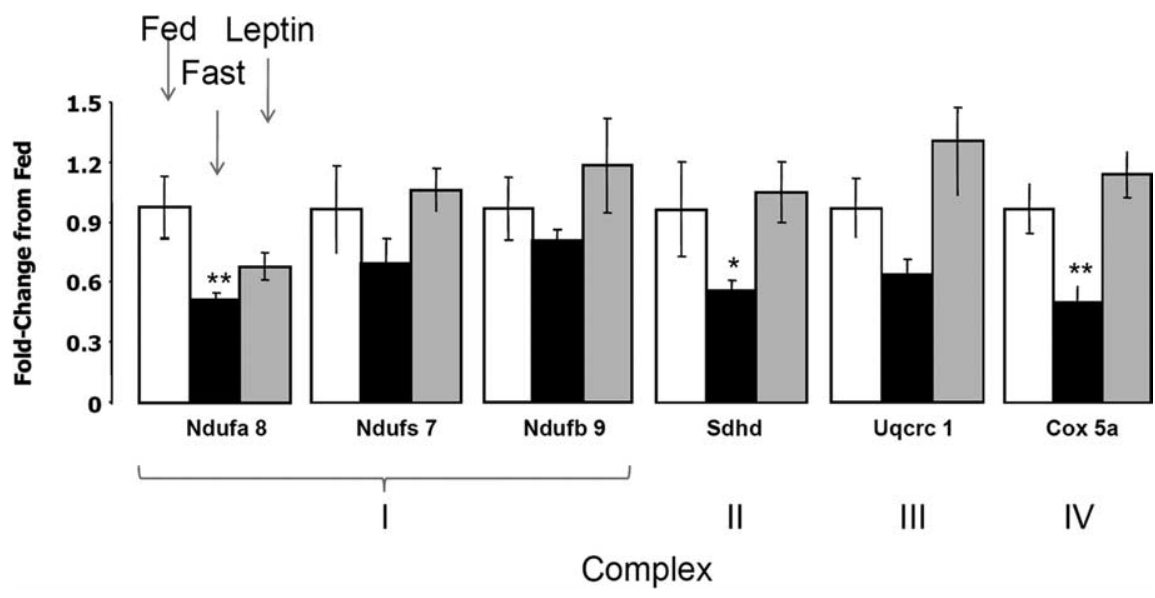

Figure 7. TaqMan quantitative PCR validation of OXPHOS genes. Bar graphs show the change in expression of six OXPHOS genes in the PVN of the hypothalamus in the fed, fasted, and leptin-treated-while-fasted state. Response is normalized to $18 \mathrm{~S}$ and is expressed in terms of fold induction of the fasted and leptin-treated expression over the fed expression. Roman numerals indicate which of the five OXPHOS complexes the genes have come from. $p$ values were calculated using a two-tailed distribution unpaired Student's $t$ test. ${ }^{*} p \leq 0.05 ;{ }^{* *} p \leq 0.01$. Data are represented as the mean \pm SE of at least six independent mice per group.

positively regulated by leptin revealed multiple genes involved in protein synthesis as well as from the mitochondrial OXPHOS pathway.

Recent evidence supports the view that protein synthesis occurs in axons, remote from the cell body, and is integral to aspects of synaptogenesis and axonal development (Piper and Holt, 2004). Thus, the fact that $9 \%$ of the genes positively regulated by leptin are involved in protein synthesis is congruent with the similar regulation of synaptic remodeling genes.

Of the 158 genes Ingenuity Pathway Analysis has categorized as being part of the OXPHOS pathway, 26 were present in the list of 438 genes. When eight of these genes were validated using Q-PCR, all the ones from complexes I-IV recapitulated the microarray data, whereas the two genes tested from complex V did not.

The hypothalamus integrates both hormonal and nutritional signals to achieve energy balance (Coll et al., 2007; Oswal and Yeo, 2007). Thus, our finding that OXPHOS gene expression decreases in the PVN in response to fasting suggests that a switch from oxidative to nonoxidative metabolism maybe important for the hypothalamic homeostatic response to nutrient deprivation and reduced leptinergic tone. A number of studies have reported that expression of OXPHOS genes are coordinately decreased in skeletal muscle from patients with T2D (Mootha et al., 2003; Patti et al., 2003), a condition closely linked with obesity (Kahn and Flier, 2000). Enormous interest is currently being expressed in the hypothalamus as a critical site for the coordinated control of both glucose homeostasis and energy balance (Obici et al., 2001; Obici and Rossetti, 2003; Lam et al., 2005). Our findings raise the possibility that regulation of OXPHOS gene expression maybe a unifying mechanism important for the control of energy balance and nutrient handling in both the hypothalamus and periphery and that dysregulation of this coordinated pattern of gene expression might underlie both obesity and diabetes.

\section{Caveats}

Although our usage of LCM has improved our "resolution" in studying gene expression in the hypothalamus, the PVN is still very heterogeneous, including both parvocellular and magnocellular neurons. Additionally, although some PVN neurons express leptin receptors, activity-dependent changes in other regions, particularly the ARC, are likely contributors to the observed transcriptional changes. This study did not allow us to discriminate between direct and indirect actions of leptin, which would require future studies profiling individually identified neurons.

\section{Conclusions}

Leptin, a circulating hormone produced in adipose tissue, influences the expression of a large number of genes within the PVN, most of which it positively regulates. In addition to certain classical neuropeptides, leptin also has striking effects on the expression of a number of genes implicated in synaptic function and/or plasticity. Finally, leptin appears to exert a generalized positive effect on the expression of genes involved in mitochondrial OXPHOS. Additional work will be required to determine which, if any, of these effects are critical for the multiple actions of leptin, including the control of bodyweight.

\section{References}

Ahima RS, Prabakaran D, Mantzoros C, Qu D, Lowell B, Maratos-Flier E, Flier JS (1996) Role of leptin in the neuroendocrine response to fasting. Nature 382:250-252.

Balthasar N, Dalgaard LT, Lee CE, Yu J, Funahashi H, Williams T, Ferreira M, Tang V, McGovern RA, Kenny CD, Christiansen LM, Edelstein E, Choi B, Boss O, Aschkenasi C, Zhang CY, Mountjoy K, Kishi T, Elmquist JK, Lowell BB (2005) Divergence of melanocortin pathways in the control of food intake and energy expenditure. Cell 123:493-505.

Besse F, Mertel S, Kittel RJ, Wichmann C, Rasse TM, Sigrist SJ, Ephrussi A (2007) The Ig cell adhesion molecule Basigin controls compartmentalization and vesicle release at Drosophila melanogaster synapses. J Cell Biol 177:843-855.

Blevins JE, Schwartz MW, Baskin DG (2004) Evidence that paraventricular nucleus oxytocin neurons link hypothalamic leptin action to caudal brain stem nuclei controlling meal size. Am J Physiol Regul Integr Comp Physiol 287:R87-R96.

Bouret SG, Draper SJ, Simerly RB (2004) Trophic action of leptin on hypothalamic neurons that regulate feeding. Science 304:108-110.

Chen L, Wang H, Vicini S, Olsen RW (2000) The gamma-aminobutyric acid type A (GABAA) receptor-associated protein (GABARAP) promotes GABAA receptor clustering and modulates the channel kinetics. Proc Natl Acad Sci U S A 97:11557-11562.

Clayton DF, George JM (1998) The synucleins: a family of proteins involved in synaptic function, plasticity, neurodegeneration and disease. Trends Neurosci 21:249-254.

Clee SM, Yandell BS, Schueler KM, Rabaglia ME, Richards OC, Raines SM, Kabara EA, Klass DM, Mui ET, Stapleton DS, Gray-Keller MP, Young MB, Stoehr JP, Lan H, Boronenkov I, Raess PW, Flowers MT, Attie AD (2006) Positional cloning of Sorcs1, a type 2 diabetes quantitative trait locus. Nat Genet 38:688-693.

Coll AP, Farooqi IS, O'Rahilly S (2007) The hormonal control of food intake. Cell 129:251-262.

Flament-Durand J (1980) The hypothalamus: anatomy and functions. Acta Psychiatr Belg 80:364-375.

Frey D, Laux T, Xu L, Schneider C, Caroni P (2000) Shared and unique roles of CAP23 and GAP43 in actin regulation, neurite outgrowth, and anatomical plasticity. J Cell Biol 149:1443-1454.

Gao Q, Mezei G, Nie Y, Rao Y, Choi CS, Bechmann I, Leranth C, ToranAllerand D, Priest CA, Roberts JL, Gao XB, Mobbs C, Shulman GI, Diano S, Horvath TL (2007) Anorectic estrogen mimics leptin's effect on the rewiring of melanocortin cells and Stat 3 signaling in obese animals. Nat Med 13:89-94. 
Goodarzi MO, Lehman DM, Taylor KD, Guo X, Cui J, Quiñones MJ, Clee SM, Yandell BS, Blangero J, Hsueh WA, Attie AD, Stern MP, Rotter JI (2007) SORCS1: a novel human type 2 diabetes susceptibility gene suggested by the mouse. Diabetes 56:1922-1929.

Hâkansson ML, Brown H, Ghilardi N, Skoda RC, Meister B (1998) Leptin receptor immunoreactivity in chemically defined target neurons of the hypothalamus. J Neurosci 18:559-572.

Harris M, Aschkenasi C, Elias CF, Chandrankunnel A, Nillni EA, Bjøorbaek C, Elmquist JK, Flier JS, Hollenberg AN (2001) Transcriptional regulation of the thyrotropin-releasing hormone gene by leptin and melanocortin signaling. J Clin Invest 107:111-120.

Hoe HS, Freeman J, Rebeck GW (2006) Apolipoprotein E decreases tau kinases and phospho-tau levels in primary neurons. Mol Neurodegener $1: 18$.

Holder JL Jr, Butte NF, Zinn AR (2000) Profound obesity associated with a balanced translocation that disrupts the SIM1 gene. Hum Mol Genet 9:101-108.

Horvath TL, Gao XB (2005) Input organization and plasticity of hypocretin neurons: possible clues to obesity's association with insomnia. Cell Metab $1: 279-286$

Huszar D, Lynch CA, Fairchild-Huntress V, Dunmore JH, Fang Q, Berkemeier LR, Gu W, Kesterson RA, Boston BA, Cone RD, Smith FJ, Campfield LA, Burn P, Lee F (1997) Targeted disruption of the melanocortin-4 receptor results in obesity in mice. Cell 88:131-141.

Irizarry RA, Hobbs B, Collin F, Beazer-Barclay YD, Antonellis KJ, Scherf U, Speed TP (2003) Exploration, normalization, and summaries of high density oligonucleotide array probe level data. Biostatistics 4:249-264.

Isse T, Ueta Y, Serino R, Noguchi J, Yamamoto Y, Nomura M, Shibuya I, Lightman SL, Yamashita H (1999) Effects of leptin on fasting-induced inhibition of neuronal nitric oxide synthase mRNA in the paraventricular and supraoptic nuclei of rats. Brain Res 846:229-235.

Joe MK, Lee HJ, Suh YH, Han KL, Lim JH, Song J, Seong JK, Jung MH (2008) Crucial roles of neuronatin in insulin secretion and high glucose-induced apoptosis in pancreatic beta-cells. Cell Signal 20:907-915.

Joseph R, Dou D, Tsang W (1994) Molecular cloning of a novel mRNA (neuronatin) that is highly expressed in neonatal mammalian brain. Biochem Biophys Res Commun 201:1227-1234.

Kahn BB, Flier JS (2000) Obesity and insulin resistance. J Clin Invest 106:473-481.

Kublaoui BM, Gemelli T, Tolson KP, Wang Y, Zinn AR (2008) Oxytocin deficiency mediates hyperphagic obesity of Sim 1 haploinsufficient mice. Mol Endocrinol 22:1723-1734.

Kullmann DM, Lamsa KP (2007) Long-term synaptic plasticity in hippocampal interneurons. Nat Rev Neurosci 8:687-699.

Lam TK, Schwartz GJ, Rossetti L (2005) Hypothalamic sensing of fatty acids. Nat Neurosci 8:579-584.

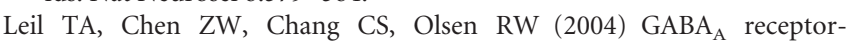
associated protein traffics $\mathrm{GABA}_{\mathrm{A}}$ receptors to the plasma membrane in neurons. J Neurosci 24:11429-11438.

Michaud JL, Rosenquist T, May NR, Fan CM (1998) Development of neuroendocrine lineages requires the bHLH-PAS transcription factor SIM1. Genes Dev 12:3264-3275.

Michaud JL, Boucher F, Melnyk A, Gauthier F, Goshu E, Lévy E, Mitchell GA, Himms-Hagen J, Fan CM (2001) Siml haploinsufficiency causes hyperphagia, obesity and reduction of the paraventricular nucleus of the hypothalamus. Hum Mol Genet 10:1465-1473.

Mootha VK, Lindgren CM, Eriksson KF, Subramanian A, Sihag S, Lehar J, Puigserver P, Carlsson E, Ridderstråle M, Laurila E, Houstis N, Daly MJ, Patterson N, Mesirov JP, Golub TR, Tamayo P, Spiegelman B, Lander ES, Hirschhorn JN, Altshuler D, Groop LC (2003) PGC-1alpha-responsive genes involved in oxidative phosphorylation are coordinately downregulated in human diabetes. Nat Genet 34:267-273.

Nielsen MS, Keat SJ, Hamati JW, Madsen P, Gutzmann JJ, Engelsberg A Pedersen KM, Gustafsen C, Nykjaer A, Gliemann J, Hermans-Borgmeyer I, Kuhl D, Petersen CM, Hermey G (2008) Different motifs regulate trafficking of SorCS1 isoforms. Traffic 9:980-994.

Obici S, Rossetti L (2003) Minireview: nutrient sensing and the regulation of insulin action and energy balance. Endocrinology 144:5172-5178.

Obici S, Feng Z, Tan J, Liu L, Karkanias G, Rossetti L (2001) Central melanocortin receptors regulate insulin action. J Clin Invest 108:1079-1085.

O’Malley D, MacDonald N, Mizielinska S, Connolly CN, Irving AJ, Harvey J (2007) Leptin promotes rapid dynamic changes in hippocampal dendritic morphology. Mol Cell Neurosci 35:559-572.

Oort PJ, Knotts TA, Grino M, Naour N, Bastard JP, Clément K, Ninkina N, Buchman VL, Permana PA, Luo X, Pan G, Dunn TN, Adams SH (2008) Gamma-synuclein is an adipocyte-neuron gene coordinately expressed with leptin and increased in human obesity. J Nutr 138:841-848.

Oswal A, Yeo GS (2007) The leptin melanocortin pathway and the control of body weight: lessons from human and murine genetics. Obes Rev 8:293-306.

Patti ME, Butte AJ, Crunkhorn S, Cusi K, Berria R, Kashyap S, Miyazaki Y, Kohane I, Costello M, Saccone R, Landaker EJ, Goldfine AB, Mun E, DeFronzo R, Finlayson J, Kahn CR, Mandarino LJ (2003) Coordinated reduction of genes of oxidative metabolism in humans with insulin resistance and diabetes: potential role of PGC1 and NRF1. Proc Natl Acad Sci U S A 100:8466-8471.

Paxinos G, Franklin KBJ (2001) The mouse brain in stereotaxic coordinates, Ed 2. San Diego: Academic.

Pinto S, Roseberry AG, Liu H, Diano S, Shanabrough M, Cai X, Friedman JM, Horvath TL (2004) Rapid rewiring of arcuate nucleus feeding circuits by leptin. Science 304:110-115.

Piper M, Holt C (2004) RNA translation in axons. Annu Rev Cell Dev Biol 20:505-523.

Poliak S, Gollan L, Martinez R, Custer A, Einheber S, Salzer JL, Trimmer JS, Shrager P, Peles E (1999) Caspr2, a new member of the neurexin superfamily, is localized at the juxtaparanodes of myelinated axons and associates with $\mathrm{K}^{+}$channels. Neuron 24:1037-1047.

Stepanyan Z, Kocharyan A, Behrens M, Koebnick C, Pyrski M, Meyerhof W (2007) Somatostatin, a negative-regulator of central leptin action in the rat hypothalamus. J Neurochem 100:468-478.

Sternson SM, Shepherd GM, Friedman JM (2005) Topographic mapping of $\mathrm{VMH} \rightarrow$ arcuate nucleus microcircuits and their reorganization by fasting. Nat Neurosci 8:1356-1363.

Stöhr H, Berger C, Fröhlich S, Weber BH (2002) A novel gene encoding a putative transmembrane protein with two extracellular CUB domains and a low-density lipoprotein class A module: isolation of alternatively spliced isoforms in retina and brain. Gene 286:223-231.

Suh YH, Kim WH, Moon C, Hong YH, Eun SY, Lim JH, Choi JS, Song J, Jung MH (2005) Ectopic expression of Neuronatin potentiates adipogenesis through enhanced phosphorylation of cAMP-response element-binding protein in 3T3-L1 cells. Biochem Biophys Res Commun 337:481-489.

Wu ZJ, Irizarry RA, Gentleman R, Martinez-Murillo F, Spencer F (2003) A model-based background adjustment for oligonucleotide expression arrays. John Hopkins University, Department of Biostatistics Working Papers, Baltimore, MD.

Yamamoto S, Morimoto I, Kai K, Arao T, Fujihira T, Morita E, Kannan H, Eto S (1999) Centrally administered murine leptin stimulates plasma arginine-vasopressin secretion and increases the level of mRNA expression in the supraoptic nucleus of conscious rats. Neuroendocrinology 70:207-212. 